\title{
Algunos intentos por escribir sobre Beatriz Sarlo*
}

\section{Some Attempts to Write about Beatriz Sarlo}

Sylvia Saitta ${ }^{a}$

Universidad de Buenos Aires, Argentina

sylviasaitta@gmail.com

ORCID: https://orcid.org/0000-0002-8086-396X

DOI: https://doi.org/10.11144/Javeriana.cl24.aibs

Recibido: 26 Mayo 2017

Aceptado: 12 Agosto 2017

\section{Resumen:}

Este artículo estudia la trayectoria intelectual de Beatriz Sarlo a través de la lectura de sus ensayos, sus escritos académicos y sus artículos periodísticos. A partir de esto, propone una periodización de sus diferentes etapas de intervención pública, un análisis de los variados modos de interpelar al lector y una interpretación de las distintas instancias de construcción de su escritura.

Palabras clave: Beatriz Sarlo, crónica periodística, crítica literaria, análisis cultural, literatura argentina.

\section{Abstract:}

This article studies Beatriz Sarlo's intellectual trajectory through her essays, her academic writings, and her newspaper articles. It proposes a periodization of her different stages of public intervention, an analysis of the varied ways she uses for questioning the reader, and an interpretation of the diverse instances of construction of her writing.

Keywords: Beatriz Sarlo, journalistic chronicle, literary criticism, cultural analysis, Argentine literature.

\section{La única nota que me era posible escribir sobre Arlt deberia reflejar mi imposibilidad de escribirla.}

Oscar Masotta

Escribir para pensar. O quizás, mejor, escribir para entender. En estas tres palabras puede resumirse la vida pública de Beatriz Sarlo. Su escritura - los modos de escribir, pero también los objetos, los temas, los problemas sobre los cuales escribir - da cuenta de momentos clave en la historia de los vínculos entre el intelectual y el académico, entre la intervención en la esfera pública y el saber especializado.

Como es sabido, Sarlo regresó a la Universidad de Buenos Aires en 1984 como profesora titular de la materia Literatura Argentina II y como investigadora del Conicet. Su actividad académica y su intervención intelectual eran, en ese entonces, parte de un mismo proyecto; por eso, los libros que publicó durante diez años - El imperio de los sentimientos (1985), Una modernidad periférica (1988), La imaginación técnica (1992), Borges, un escritor en las orillas (1993) - estudian las primeras décadas del siglo veinte para pensar, también, el presente y el futuro de la Argentina después de la dictadura. Esas investigaciones se realizaron en el marco de un proceso de reconstrucción de la universidad pública que también era nuevo. Expulsados de la universidad durante la dictadura, volvían a ella tanto quienes habían sido parte de la militancia estética y política de los años setenta como aquellos que habían abandonado los claustros después del golpe de Estado de 1966. Basta asomarse al segundo tomo de los diarios de Emilio Renzi para notar cómo, en los "años felices" que abarcan el período de 1968-1975, la universidad era un escenario poco frecuente para la intervención de escritores e intelectuales que estaban más ligados a la actividad periodística y editorial que a la vida académica (véase Piglia). En cambio, en los primeros años de la democracia abierta en diciembre de 1983, la universidad se transformó en parte activa de la esfera pública. Académicos, investigadores y científicos recuperaron la

Notas de autor

\footnotetext{
a Autora de correspondencia. Correo electrónico: sylviasaitta@gmail.com
} 
confianza en que, desde la propia especialidad, podían pensarse los problemas políticos, sociales y culturales que los diferentes sectores de la sociedad estaban debatiendo, y consideraron que esa tarea era una parte inherente del ser universitario. ${ }^{1}$

En este marco, el estudio sobre la novela sentimental implicó una discusión, tanto con la celebración populista de izquierda como con los modos en que habían sido abordados los medios masivos y la industria cultural del peronismo durante los años setenta. La investigación sobre las vanguardias literarias, los procesos de modernización urbana y la cultura de mezcla de una ciudad periférica tenía como principal pregunta cómo ser un país moderno:

"Está claro - escribe Sarlo en el prólogo a La imaginación técnica- que la preocupación que guió [sic] este trabajo remite a una pregunta que hoy nos interesaría a todos responder sobre las posibilidades abiertas en la Argentina de las primeras décadas de este siglo, probablemente un país que tuerce muy radicalmente su curso en los años cuarenta." (14)

Mucho se ha escrito sobre esto (Pagni y Von der Walde, 1995; Pistacchio, 2005; Vázquez, 1988).

Se trató, como Sarlo afirma y reitera una y otra vez, de un momento político optimista, pronto clausurado, que reveló que el punto de partida de esas investigaciones - las hipótesis sobre una democracia inclusiva e igualitaria, las políticas culturales, el lugar de la escuela pública, la rearticulación del entramado social— estaba equivocado:

"Era un período fascinante de la Argentina que, visto en 1983 cuando yo empecé a trabajar los textos de La imaginación técnica, me hicieron pensar que a lo mejor la democracia podía trazar líneas hacia atrás, a ese país muy galvanizado alrededor de ciertos fenómenos culturales [...]. ¿ ¿Podía recuperarse algo de ese país? Me preguntaba en los ochenta. La pregunta estaba equivocada, eso estaba clausurado. Pero de alguna manera esa pregunta equivocada me comunicaba con el presente [...] qué hubo de interesante en ese pasado, qué de moderno y de liberador para algunos sectores que podía transferirse, de la manera en que se transfieren las cosas, al presente. Ahí arranqué. (Moreno 2)

Una modernidad periférica es un libro que está hecho sobre una idea (un deseo) equivocada, no en la descripción de los autores ni en los análisis, sino en que el libro fue escrito para demostrar que, así como la Argentina tuvo ese momento vigoroso de las vanguardias, iba a volver a tenerlo, que existía esa posibilidad. Hoy creo que es una hipótesis totalmente equivocada, demasiado optimista. Cuando apareció, Adolfo Prieto me dijo "no te ocupás del golpe del 30 " y le respondí que no lo hacía porque de todas maneras la Argentina se recupera rápidamente de ese golpe, pero quizá tendría que ocuparme de ese golpe porque esa era la Argentina que iba a repetirse. (Malumián 19)

La distancia que siento respecto de Modernidad periférica [sic] reside en que mi hipótesis sobre la Argentina del momento en que escribía (no del momento sobre el que escribía) estaba equivocada [...]. La hipótesis sobre el presente de la escritura, que yo tenía al escribirlo, estaba equivocada. No la hipótesis sobre los años 20 , que eso lo diga otro, pero sí sobre mis condiciones de enunciación. Los 90 me sacaron rápidamente de esa ensoñación halagadora." (López y Scolnik 21)

En una entrevista que Adriana Bocchino y Mónica Bueno le realizaron en 1997, Sarlo hace referencia a los momentos previos a la escritura de Escenas de la vida posmoderna, publicado en 1994. Cuenta que había escrito una columna para la revista Página/30 y que había querido volver sobre esos temas: "Yo no sabía muy bien dónde iba a terminar, pero de hecho durante seis meses me pasé dando vueltas. Como había publicado La imaginación técnica dije: 'Bueno, no hago nada'" (Bocchino y Bueno 186). No hacer nada. Cumplida la exigencia académica, la escritura que circulaba por fuera de ese circuito era, en los comienzos de los años noventa, ese no hacer nada: un dejarse llevar, un dar vueltas, un escribir en otro tono, sobre otros temas, para otros lectores.

Desde ese momento, y a lo largo de una década, la escritura de Sarlo avanzó sobre dos andariveles porque eran dos sus espacios de enunciación: los trabajos de investigación académica y las ponencias en congresos, por un lado; los ensayos y los artículos periodísticos en diarios y revistas, por otro. Dos ámbitos que Sarlo describe, en la "Advertencia" de Tiempo presente que escribirá en 2001, como los "dos tiempos" de su escritura:

“Mientras enseño literatura en la Universidad de Buenos Aires, escribo en dos tiempos: los capítulos de algún libro futuro, como La máquina cultural lo fue en 1998, y, hoy, un ensayo todavía bastante secreto que (espero) dejará de serlo alguna vez; escribo también textos breves, que salen de los diarios y van a ellos, textos de intervención la mayor parte. Algún lector podrá verlos como prosa periodística; otro quizá les haga el favor de encontrar algo más. Varios de los artículos que fueron publicados 
en Punto de Vista también pertenecen a este tipo de intervenciones, aunque sean algo más largos y su argumentación sea un poco más complicada. Se trata siempre del presente o de las formas en que la historia ha marcado el presente. Pero de lo que se trata, en verdad, es de pensar velozmente y escribir con esa misma velocidad. Probablemente sean estos los textos con los que mantengo una relación que es la más intensa y la más infiel." (9)

En efecto, a partir de 1993, mientras enseña literatura argentina en la carrera de letras de la Facultad de Filosofía y Letras; mientras explora las revistas de espectáculos de los años cuarenta para analizar la figura de Eva Duarte; mientras lee cartas y testimonios de Victoria Ocampo; mientras vuelve a leer a Borges, Sarlo escribe una columna titulada "Opinión”, para Página/12, y la sección "Caza de citas" para Página/30(ver anexo 1).

"Caza de citas" se presenta en Página/30 en septiembre de 1993: "Desde este mes, Beatriz Sarlo se convierte en cazadora de citas y ofrecerá —en estas páginas - reflexiones a partir de célebres, o no tanto, pronunciamientos ajenos. Adivinar el nombre detrás de las palabras será, apenas, parte de la diversión” (24). ${ }^{2}$ Cada nota se abre entonces con una cita ajena de la que no se menciona al autor; la revista ofrece varias opciones y recién en el número siguiente revela el nombre. A esta sección, que se extiende hasta mediados de 1996, le sigue "Cuadros de costumbres", publicada entre septiembre de 1996 y febrero de 1998.

Las notas de "Cazas de citas", y la reescritura de estas notas, están en la base de Escenas de la vida posmoderna (1994) e Instantáneas: medios, ciudad y costumbres en el fin de siglo (1996). Ya en Escenas de la vida posmoderna estaban los comienzos de un plan y una metodología de trabajo que se irían afirmando en los libros que le siguen. Hasta entonces, como antes se dijo, las preguntas eran sobre la modernidad inconclusa, periférica y argentina de los comienzos del siglo veinte porque esas preguntan daban respuesta al presente del alfonsinismo. En la posmodernidad del período menemista, el método de trabajo es otro:

"Se trata más bien de preguntar para hacer ver y no de preguntar para encontrar, de inmediato, una guía para la acción. No son preguntas del qué hacer, sino del cómo armar una perspectiva para ver [...]. Mirar en detalle, en una relación de cercanía, pero no de complicidad, captar la escena desde el lugar más próximo posible, es una cuestión de método [...]. Solo a partir de la mirada que Walter Benjamin llamó “microscópica”, pude convencerme de que se podían evitar las generalizaciones blandas sobre la cultura posmoderna, ya sea en tono optimista o de condena." (Instantáneas 8)

El propósito es mirar de cerca el presente en dos de sus escenarios fundamentales: los medios audiovisuales y el espacio urbano. El método es la crítica cultural como una de las variantes del discurso de los intelectuales que permite una mirada alejada tanto de la celebración populista como de los prejuicios elitistas. Los instrumentos de trabajo son los que provienen de la crítica literaria y el análisis de la cultura. El resultado es una nueva forma narrativa, sin notas al pie, sin citas ni comillas, sin exposiciones bibliográficas.

A su vez, si el propósito es mirar de cerca, hay un sujeto que mira pantallas, videojuegos, programas de televisión, y hay un sujeto que camina la ciudad, los shoppings, los locales de juegos. Por eso, como dice Sarlo en el prefacio a Instantáneas, "fue inevitable que este libro tuviera un acento personal" (8). Asoma así una primera persona que, en Tiempo presente, de 2001, y, sobre todo, en las crónicas de la revista Viva, escritas entre 2004 y 2007, ocupará uno de los centros de la escena.

El avance de la primera persona es gradual; avanza y retrocede; se esconde detrás de otras voces; es un juego de malabaristas entre la prueba y el error. No es fácil arribar a la primera persona, y Sarlo lo sabe.

Porque la escritura cambia, porque los objetos de reflexión son otros, porque los espacios de enunciación van dejando de ser los congresos y las revistas universitarias para ocupar las columnas de los diarios y las revistas, el vínculo que Sarlo imaginaba entre los intelectuales y la academia entra en crisis. Si en 1984 la práctica académica y la labor intelectual eran parte de un mismo proyecto, diez años después Sarlo sostiene que el ingreso de los intelectuales a la academia implica el abandono tanto del escenario que les era propio - la esfera pública - como del carnet de identidad: en la academia, dice Sarlo, trabajan como expertos y no como intelectuales. ¿Quiénes son los expertos? Aquellos que "no se presentan como portadores de valores generales que trasciendan la esfera de su expertise”, y que, por lo tanto, no se hacen cargo de los resultados 
políticos y sociales de los actos fundados en el saber específico de su especialización científica o tecnológica (Escenas 181).

No obstante, la incomodidad no está, todavía a mediados de los años noventa, en la investigación académica o en la preparación de las clases universitarias, sino que esa incomodidad aparece frente a las modas teóricas que se reproducen en los modos de leer - y, por eso, el llamado a "olvidar a Benjamin", en 1995, es toda una declaración de principios-, o en la reiteración de prácticas movidas más por la indolencia y el acatamiento de pautas de funcionamiento que no se cuestionan, que por la pasión intelectual:

\begin{abstract}
"Después de 1984, Buenos Aires se convirtió en un tinglado de conferencias, simposios, mesas redondas. Escuchar o pronunciar conferencias pasó a ser parte del oficio intelectual y del hábito del público. El empresariado de las conferencias cambió la vida literaria y la vida académica. Todo se volvió bastante internacional, con viajeros frecuentes que establecieron una rutina sudamericana para julio y agosto, cuando son las vacaciones en el norte. Las universidades, por su parte, se sometieron a una especie de pauta académica por la que los congresos, simposios o paneles son una parte esencial del curriculum $[s i c]$ de sus profesores, una parte que obliga a condensaciones milagrosas en intervenciones de quince o veinte minutos, con diez minutos absurdamente fugaces para una discusión general." (Tiempo presente 183)
\end{abstract}

Esas prácticas académicas no solo incomodan, sino que dejan afuera lo que, para Sarlo, es fundamental: la experimentación con la escritura, la libertad de moverse en diferentes registros, esa tensión más propia del ensayo que del corsé de las formas al que obligan las reglas del sistema científico (Giordano 92). En abierta confrontación con esa escritura que congela todo lo que toca y que es leída solo por los colegas, Sarlo escribe La máquina cultural. Maestras, traductores y vanguardistas, en 1998. Mientras que en Escenas de la vida posmoderna e Instantáneas Sarlo utilizó una metodología que ya conocía (una crítica de la cultura signada por Barthes y Benjamin) para leer los objetos del presente, en La máquina cultural vuelve a pensar el pasado, pero para pensar el presente: vuelve a la modernidad para reflexionar sobre el sistema educativo nacional, la articulación entre centros y periferias culturales, el diálogo imposible entre vanguardia estética y radicalización política. Y lo hace de otro modo. La metodología es la misma (leer los detalles), pero el salto experimental se da en la escritura. Principalmente en el primer capítulo del libro, en el que Sarlo inventa una primera persona ficcional para contar una historia de vida que ilumina, con otra luz, los avatares de la escuela pública, el laicismo, el magisterio como una carrera del ascenso social de las mujeres y los procesos de integración de los inmigrantes a través de los símbolos nacionales.

En un debate acerca de ese trabajo sobre la educación argentina, Adrián Gorelik le pregunta el por qué de esa elección de narrar usando la primera persona de la maestra. Sarlo responde que no tiene ninguna teoría que encuadre esa decisión; que aquello mismo que escribió en primera persona podría haber sido expuesto en tercera; que los motivos - imposibles de enmarcar en razones académicas o científicas - son puramente personales:

"En realidad, la búsqueda de la voz fue la búsqueda de un tipo de escritura que me permitiera a mí pasarla bien mientras hacía la investigación. Esto es todo. No pienso que en la voz haya más verdad que en otro tipo de relatos, ni pienso que en la primera persona haya más verdad que en la tercera ni que en la segunda, no pienso en ninguna autenticidad de la voz ni en que se reconstruye ninguna autenticidad de la voz. A mí me resultó más atractivo tomar por el lado de la voz [...]. Si lo sustento de algún modo es en razones de escritura personales." ("Debate” 199)

Los relatos ayudan a entender. La organización narrativa, el cruce de fuentes diversas, el entramado de voces, los usos de la ficción, ensanchan los límites de la escritura académica, colocándola en el borde. El deseo ficcional, del que habla Sarlo en una entrevista que le realiza Graciela Speranza en abril de 1998, presupone una certeza: narrar permite un acercamiento más preciso a nudos significativos de la historia que los métodos de interpretación avalados por la norma científica. Las historias son un paisaje que permite ver mejor.

Cuando en el 2001 Sarlo advertía que escribía "en dos tiempos" para referirse a sus dos escrituras, la investigación académica y la periodística, no sabía que, pocos años después, esa expresión, la de escribir en dos tiempos, sería, como en un partido de fútbol, la descripción, ya no de dos momentos simultáneos, sino de dos etapas sucesivas. Un segundo tiempo se abre a partir de 2003, cuando Sarlo renuncia a la Universidad de 
Buenos Aires: el "mientras enseño literatura", con que se abría la "Advertencia" de Tiempo presente, permitía sostener esos dos tiempos en una simultaneidad que comienza a desanudarse cuando Sarlo abandona su materia Literatura Argentina II de la Facultad de Filosofía y Letras ${ }^{3}$ y que termina, poco después, con su jubilación del Conicet y el cierre de Punto de Vista.

Desde entonces, librada del peso de la academia, la escritura de Sarlo se torna más autobiográfica; la primera persona que, con énfasis, aparecía en los márgenes de los libros —en los prólogos, en los posfacios, en las notas al pie-, o se disimulaba en perífrasis y rodeos — como sucedía con la voz de la tía materna en el primer capítulo de La máquina cultural o en los retratos del cuarto capítulo de Escenas de la vida posmodernapasa a ocupar el centro de los propios textos. ${ }^{4}$ Si en 2001, cuando relee a Raymond Williams para escribir el prólogo a la primera traducción al español de El campo y la ciudad, Sarlo decía que ese libro era un texto personal, era porque en él Williams encontraba "en el enigma autobiográfico su impulso" (12). La pasión y la excepción, escrito poco después, coloca su punto de partida en ese mismo impulso autobiográfico que le permite a Sarlo asumir sin prejuicios la primera persona y volver, también sin prejuicios, a su propia vida: "Hay razones biográficas en el origen de este libro y conviene ponerlas de manifiesto. Formo parte de una generación que fue marcada en lo político por el peronismo y en lo cultural por Borges. Son las marcas de un conflicto que, una vez más, trataré de explicarme" (9). ${ }^{5}$

Sin embargo, no es en los libros donde Sarlo comienza a jugar su "segundo tiempo", sino en la columna de opinión de Viva, la revista dominical de Clarín, donde escribe esos ejercicios de prosa narrativa que, como Borges en la Revista Multicolor de los Sábados del diario Crítica, elige ensayar una nueva escritura en las páginas de la revista de un diario leído por miles lectores: "Es todo un experimento de escritura. Para mí, en un punto, el más interesante que he hecho dado que está absolutamente lejano de cualquier otro experimento anterior" (Malumián 19).

Desde julio de 2004, y durante tres años, Sarlo hace de la columna de Viva un espacio de reflexión sobre el presente. Pero no sobre todo el presente: la política, por ejemplo, como sucedía en las aguafuertes porteñas de Roberto Arlt, queda afuera de estas notas _ “Además está la convención propia de Viva: no se habla de política" (Malumián 19), afirma Sarlo-y se desplaza a otros ámbitos: a La Nación, primero, y a Perfil, después. Lo que a Sarlo le interesa en Viva es volver sobre algunos de los temas que fueron centrales en sus investigaciones - la educación pública, los cambios en los modos de leer, la pobreza urbana, el impacto de la tecnología en las costumbres populares-, pero dirigidos, esta vez, a un público ampliado. Volver también, y esto es lo nuevo de Viva, a los recuerdos de su infancia, al relato de sus viajes, a las voces y las lecturas de la niñez. El hilo conductor de estas notas es la primera persona: es esa primera persona, la de Beatriz Sarlo, la que camina la ciudad, se interna en un locutorio, escucha conversaciones ajenas, asiste como espectadora a una ópera en el Colón o a un espectáculo de jazz callejero, comenta el último libro que ha leído, observa a quienes viven en la calle o venden estampitas en los subtes. Y es esa primera persona la que también recuerda las vacaciones de infancia en Deán Funes, el impacto de conocer el mar a los 16 años, el primer viaje a París, a Estados Unidos, a la cordillera, a Jujuy, a Catamarca, a Cochabamba, a Colón y a Bolivia.

El uso de la primera persona es indispensable para la creación de un pacto de interlocución con lectores que, para Sarlo, son nuevos. Por eso se muestra a sí misma para conocer a quienes están del otro lado; ofrece un recuerdo, una opinión, un relato para recibir también, ella, un recuerdo, una opinión, un relato: "Cuando acepté el trabajo y empecé a recibir los mensajes de los lectores a la casilla de Viva me di cuenta de que era todavía más amplio. Era un mundo absolutamente desconocido” (Malumián 20).

Y porque son desconocidos, las crónicas conservan la marca del tanteo: al comienzo, son pedagógicas y presuponen un lector ajeno a las prácticas de la cultura alta (describe, por ejemplo, cómo es el Teatro Colón por dentro); $;$ más adelante, en cambio, se liberan de la descripción y avanzan sobre temas, referencias y saberes que se consideran compartidos con el lector. ${ }^{7}$ Este cambio en la interlocución se explica en las crónicas: Sarlo no solo dice que recibe mails de sus lectores, y que por eso sabe lo que piensan o preguntan, sino que esos lectores 
son representados en las mismas crónicas. Cuando el 22 de mayo de 2005 aparece la primera representación de un lector, Sarlo también se representa a sí misma en diálogo directo con ese lector, sin las mediaciones del correo electrónico o la carta escrita:

"El semáforo en rojo permitió que la conversación se prolongara un poco más; nos despedimos en la esquina, después de cruzar la avenida. Habíamos viajado juntas en el subterráneo y, durante el transcurso de las últimas dos estaciones, ella se sentó a mi lado "para charlar, ya que se daba la oportunidad", según me dijo. No nos conocíamos, aunque ahora sé que se llama Mercedes. Debe tener más o menos cuarenta años. Y lee esta revista dominical.” ("Las dos preguntas” 58)

Algo similar hace Fray Mocho, quien se dirige al lector para explicar por qué su sección, en el diario La Mañana de La Plata, se titula "Instantáneas metropolitanas":

"Ahora ya no soy aquel trabajador de antes, que usted conoció echando el alma sobre las mesas de redacción, sino uno de los tantos vagos que caminan por las calles de la ciudad - tan llenas de cosas curiosas - a la caza de algo que hacer. Mi correspondencia, pues, no será científica ni literaria, sino sencillamente informativa; me dejaré de libros, de escabrosidades políticas, de investigaciones prolijas y minuciosas respecto a cómo se pasan las cosas en la realidad de la vida y me limitaré pura y exclusivamente a pintárselas como yo las veo, a transmitirle los comentarios que oigo por ahí; a ser, resumiendo, un fotógrafo que saca vistas instantáneas para La Mañana." (59)

Arlt también describió su crónica en respuesta a la carta de un lector que le preguntaba por qué sus notas se llamaban "aguafuertes":

"Me escribe el señor Olmedilla, refiriéndose a una tertulia de café donde se comentan y discuten mis notas [...]. Cuando usted me pregunta si lo que yo escribo son o no aguafuertes, no sé si decirle que sí o que no. Sé que a veces, a cierta gente, mis notas le pican como ácido nítrico. Y con este ácido es con el que se graba en metal el diseño de esa clasificación: aguafuertes." (6)

Sarlo incorpora el diálogo con una lectora para definir su columna como un "boceto a mano alzada":

"Le dije a Mercedes que yo escribía la columna básicamente como ejercicio realizado desde un mirador urbano al ras de la calle; que era una especie de diario no de lo que me sucedía, sino de lo que estaba viendo que le pasaba a otros, escenas fugaces para mí, aunque repetidas para algunos de sus protagonistas. En ese sentido, lo escrito era lo que en pintura se llama boceto a mano alzada, el dibujo rápido que se realiza sobre un block de papel canson, a lápiz, en el lugar de los hechos, sin apoyar la hoja en una mesa, con el brazo y la mano suspendidas sobre la superficie blanca; o también, si se piensa en la fotografía, instantáneas, imágenes que probablemente no tengan otro valor que el de haber captado lo que sucede en un momento, si eso que sucede tiene algo de particular, no un gran significado, sino una punta de sentido que parece valer la pena, aunque nunca se esté demasiado seguro porque la instantánea puede ser completamente banal y la escena que se pensó significativa no revela completamente nada. No hay foto más tonta que una mala instantánea. Todo depende, más que de la destreza, del repentismo, ese reflejo que lleva la orden del ojo al dedo que aprieta el disparador de la cámara." ("Las dos preguntas" 58)

De Fray Mocho y Roberto Arlt a Beatriz Sarlo; de las instantáneas metropolitanas y las aguafuertes porteñas a los bocetos a mano alzada: una historia de la crónica periodística podría comenzar con ese título.

Mientras Sarlo publicaba sus notas en Viva, y probablemente bajo el impacto de las críticas que esas columnas generaron en los círculos universitarios — sobre todo en un indignado Jorge Panesi, que le dedicó ponencias y artículos a tan espinoso tema-, quien esto escribe decidió compilar los artículos de Sarlo dedicados a la literatura argentina que habían sido publicados en revistas académicas, en Punto de Vista y en suplementos culturales. Las prevenciones de Sarlo sobre este retroceso a un tiempo anterior - al tiempo de la escritura académica y la docencia universitaria - se leen en el prólogo:

"No tengo casi nada más que agregar, excepto que fue a Sylvia Saítta a quien primero se le ocurrió este libro y organizó las cosas de tal modo que finalmente fue más fácil hacerlo de lo que yo suponía. Tengo que agradecérselo incluso si los lectores juzgan que fue un error, porque se trató también de un acto de amistad." (Escritos sobre literatura 11)

Escritos sobre literatura argentina, de 2007, aun cuando, como bien lo señaló Ivonne Bordelois, está lejos de la rigidez de la escritura académica, ${ }^{8}$ es, efectivamente, un paso hacia atrás. Los lectores - los pares, los colegas, los estudiantes universitarios, los críticos literarios - lejos están de quienes Sarlo imaginó a la hora 
de liberar su escritura, esos "lectores radicalmente desconocidos [que] son pura fantasía, pura invención, no hay amenaza, sino un placer un poco infantil que experimenta quien escribe, una travesura, el ejercicio de una libertad fuera de la mirada de los jueces" (Link 6). El presente de la escritura es otro: son las notas escritas al correr de la pluma de Viva que pronto se convierten en el cuaderno de bitácora de La ciudad vista: mercancías y cultura urbana, de 2009, y Viajes. De la Amazonia a Malvinas, de 2014; son los apuntes de la Libreta Sarlo, esa "modesta exhibición de ideas y ocurrencias que, antes, simplemente se anotaban en libretas negras" que se publican en Bazar Americano entre el 9 enero de 2010 y el 5 de abril de 2011 -que son un contrapunto de las notas de Viva, pues en ellas campea la alta cultura, la disquisición estética, la sutileza crítica一; son las notas de discusión política que, escritas en La Nación a lo largo de tres años, devienen en La audacia y el cálculo, en 2011; y son, también, los ensayos críticos sobre literatura argentina contemporánea que, publicados en el suplemento cultural de Perfil entre octubre de 2007 y mayo de 2012, se compilan en Ficciones argentinas: 33 ensayos, en 2012. Es otro el presente de la escritura porque, para Sarlo, como le dice a Alejandro Grimson en 2012, la diferencia entre el académico y el intelectual es precisamente esa, la intervención en los medios:

"Diría que si no estás en los medios, esas intervenciones no existen. Sos puramente un académico y no un intelectual. El desafío hoy - y ése sí es un desafío nuevo de los últimos diez años- es que tenés que estar en los medios.” (71)

Y Sarlo ocupa enteramente los medios: además de escribir en diarios y revistas, participar como panelista en programas televisivos, intervenir en debates públicos, en 2011 formó parte de La otra pata, el ciclo radial conducido por Marcelo Zlotogwiazda en Radio Mitre. ${ }^{9}$

Algunos fantasmas inquietan a Sarlo cuando escribe. El primero, ya presente en sus clases cuando dictaba los teóricos en su curso de Literatura Argentina II, es el miedo a la repetición, a volver sobre los mismos argumentos, a reiterar lo ya investigado, lo ya sabido, lo ya probado. Por eso aclara todo el tiempo, para que no se malinterprete, que el lector no encontrará nada de lo ya leído en los libros anteriores - "Ningún lector que haya comprado un libro con mi nombre en la tapa en calidad de autora encontrará en esta antología un texto que se repita. Excluí todos los artículos que prepararon o siguieron a la publicación de esos libros" afirma, por ejemplo, en la introducción a Escritos sobre literatura argentina (11)_; que no revisó sus viejos apuntes para escribir algo nuevo - "Escribí este libro tratando de transmitir la felicidad y el asombro que siempre sentí ante la literatura de Saer. Por eso evité el lenguaje académico y no volví a leer ninguna de las notas, artículos y ponencias que a lo largo de las décadas yo había escrito sobre Saer", subraya en las páginas preliminares de Zona Saer (9)—; que puede volver a los autores de siempre - a Borges, a Juan José Saer, a Victoria Ocampo, también a Arlt-, pero con otras preguntas, como si fuese la primera vez.

Basta con cotejar algunas de las lecturas de Sarlo a lo largo del tiempo para ver que esto es, efectivamente, así. La lectura del Arlt de Una modernidad periférica - ese Arlt-sinécdoque de la cultura que mezcla pacíficamente los saberes del pobre y la alta cultura, y el entramado inmigratorio y a la vez porteño de la Buenos Aires del veinte- se hace trizas en el Arlt leído en el 2000, ese Arlt excéntrico que, con la violencia aprendida en Georges Sorel, sueña con volar por el aire a esa ciudad despiadada de los mismos años veinte (Sarlo, "Roberto Arlt"). Poco queda, por no decir nada, del Borges compadrito y vanguardista, cultor de la voz de sus mayores en los años veinte y artífice de las ficciones de imaginación razonada de los cuarenta, en el Borges que cifra la violencia política de los años setenta en La pasión y la excepción. Se lee siempre desde el presente y por eso el Arlt de 1988 no es el Arlt del 2000, ni el Saer contemporáneo es el Saer al que se vuelve después de que esa obra ya se ha cerrado por la muerte de su autor y los años transcurridos desde esa muerte permiten volver a su literatura, pero para leerla como si nunca antes se la hubiera leído.

De lo que se trata, para Sarlo, es de disentir consigo misma. ${ }^{10}$ De leer la literatura argentina desde el presente y de leer, a su vez, el presente de la literatura argentina. Por eso hay en Sarlo esa ansiedad de ser siempre contemporánea de su presente; de no ser, en este punto, como sus maestros Roland Barthes o David Viñas, que no pudieron o no supieron leer la ficción a partir de un momento determinado de sus vidas. Sarlo lee la literatura argentina que se escribe en el aquí y ahora como si ese ejercicio de lectura fuese, siempre, por primera 
vez. Por eso, justifica y explica esa lectura: "La crítica vive en la actualidad", dice en el Prólogo a Ficciones argentinas; "el suelo de la crítica es el presente", reitera (13). Y porque siempre es la primera vez, el riesgo es ser como "un explorador de un territorio en tiempo presente" que no gira sobre un capital depositado, sino que escribe una experiencia de lectura libre de legislaciones teóricas o críticas.

Hay también otro miedo, que es el miedo a la reescritura. Por eso, y no solo por no darles un trabajo adicional a sus lectores, Sarlo jamás corrige los libros suyos que se reeditan, como le aclara a Daniel Link cuando se reedita Siete ensayos sobre Walter Benjamin, en 2011:

"Me es completamente imposible volver a leer este libro. Como si al patético y laborioso Pierre Menard le pidieran que analizara su propia escritura del Quijote. Cuando era muy joven, vi a un gran autor nacional corrigiendo una nueva edición de una novela suya; en ese momento juré que, si alguna vez yo escribía un libro, nunca, después de editado, lo volvería a corregir. Llevé esa promesa al extremo y ahora no puedo leer ningún libro que haya escrito." (8)

En este punto, su figura es la antítesis de Ricardo Piglia y se acerca a la de César Aira: un libro futuro corregirá o ampliará el libro anterior; porque hay algo para corregir, se escribe el libro siguiente. Lo que en Escenas de la vida posmoderna fue más una intuición que una comprobación empírica sobre el funcionamiento de los shoppings en relación con el entramado urbano, se retoma - y no se reescribe- en La ciudad vista, catorce años después.

Porque no se reescribe, ni se corrige lo que ya se ha escrito, los libros que provienen de una escritura previa -las notas publicadas en diarios y revistas; los artículos que circularon en revistas culturales y académicasson iniciativas que provienen de otros: de editores, de colegas, de discípulos. ${ }^{11}$

En 1986, asistí, por primera vez, a un seminario interno de la cátedra de Literatura Argentina II. Era estudiante; estaba muy nerviosa; entendía bastante poco. Después de los primeros encuentros, en los cuales Sarlo había presentado las principales hipótesis de su investigación en curso sobre los procesos de modernización de los años veinte, pidió que cada uno definiera el tema sobre el cual iba a exponer. Elegí dedicarme a Roberto Arlt, del que solo había leído Los siete locos y Los lanzallamas, pero con quien ya me había identificado: porque había llegado al mundo de la literatura desde una casa sin bibliotecas; porque se había formado leyendo novelas populares, folletines y malas traducciones; porque aseguraba que el mundo era nuestro por prepotencia de trabajo.

Como éramos varios los que habíamos elegido a Arlt, una noche, al finalizar la reunión, Sarlo despidió al resto de los participantes del seminario diciendo: "Quédense, solamente, los arltianos". Escuché "los arltianos", pero también escuché: "los sarlianos”. Muy poco después supe que pertenecía a ambos bandos.

\section{Referencias}

Arlt, Roberto. "Aguafuertes Porteñas. El derecho de alacranear". El Mundo, 10 de diciembre de 1929, p. 6.

Bocchino, Adriana y Mónica Bueno. "Entrevista a Beatriz Sarlo". Celehis. Revista del Centro de Letras Hispanoamericanas, n. ${ }^{\circ}$ 9, 1997, pp. 163-189.

Bordelois, Ivonne. "Lúcidas miradas críticas". La Nación, 10 de junio de 2007, https://www.lanacion.com.ar/cultura /lucidas-miradas-criticas-nid915943/.

Canavese, Mariana. "Beatriz Sarlo. Política partidaria”. TXT, n. ${ }^{\circ}$ 27, 19 de septiembre de 2003, pp. 50-52.

Fray Mocho. "Instantáneas metropolitanas". La Mañana, 1 de noviembre de 1894. Recopilado en Salero criollo, tomo 1, Schapire, 1961, p. 59.

Freire, Silka. "La pasión por la escritura, la excepción de la estructura: Beatriz Sarlo y el ensayo latinoamericano del siglo XXI", VII Congreso Internacional Orbis Tertius de Teoría y Crítica Literaria, 18-20 de mayo de 2009, La Plata, Memoria Académica, http://www.memoria.fahce.unlp.edu.ar/trab_eventos/ev.3544/ev.3544.pdf.

Giordano, Alberto. "La crítica de la crítica y el recurso al ensayo". Razones de la crítica. Sobre literatura, ética y politica. Colihue, 1999, pp. 141-155. 
Grimson, Alejandro. "Entrevista. Beatriz Sarlo: el entusiasmo político y la duda intelectual". Otra Parte, n. ${ }^{\circ} 25$, verano de 2011-2012, pp. 69-76.

Link, Daniel. “Beatriz Sarlo, 'La industria Benjamin no decae”. Revista N, n. ${ }^{\circ}$ 392, 2 de abril de 2009, pp. 6-9.

López, María Pía y Sebastián Scolnik. "Beatriz Sarlo: 'Encuentro más percepción de verdad en la literatura que en la etnografía”. La Biblioteca, n. ${ }^{\circ}$ 7, primavera de 2008, pp. 10-25.

Malumián, Víctor. “Entrevista a Beatriz Sarlo”. Esperando a Godot, n. o 8, 2006, pp. 16-24.

Masotta, Oscar. "Seis intentos frustrados de escribir sobre Arlt". Hoy en la Cultura, n. ${ }^{\circ}$ 5, septiembre de 1962, p. 8.

Mondragón, Rafael. "Beatriz Sarlo: una lectora en el mundo". Memoria. Premio Internacional Pedro Henríquez Ureña 2015, editado y compilado por Luis O. Brea Franco, Ministerio de Cultura, Editora Nacional, 2016, pp. 45-56.

Moreno, María. "Beatriz Sarlo cuenta la historia de la novela rosa”. Página/12, 16 de junio de 2000, pp. 1-3.

Pagni, Andrea y Erna von der Walde. "Qué intelectuales en tiempos posmodernos o de 'cómo ser radical sin ser fundamentalista'. Aportes para una discusión con Beatriz Sarlo”. Culturas del Río de la Plata (1973-1995). Transgresión e intercambio. Lateinamerika-Studien, n. ${ }^{\circ}$ 36, Vervuet Verlag, 1995, pp. 287-312.

Panesi, Jorge. "Hegemonía, excepciones y trivialidades en la crítica cultural argentina". Actas digitales del Congreso Internacional "Debates actuales: las teorias criticas de la literatura y la lingüistica", Universidad de Buenos Aires, Facultad de Filosofía y Letras, 2004.

Piglia, Ricardo. Los diarios de Emilio Renzi. Los años felices. Anagrama, 2016.

Pistacchio, Romina. Una perspectiva para ver. El sujeto critico de Beatriz Sarlo. Corregidor, 2005.

Reynoso, Mónica. "Beatriz Sarlo. Entrevista”. Revista de Lengua y Literatura, n. ${ }^{\circ}$ 3, mayo de 1988, pp. 55-60.

Sarlo, Beatriz. “iAl Colón!”. Viva, 1 de agosto de 2004, p. 58.

Sarlo, Beatriz. Borges, un escritor en las orillas. Ariel, 1995.

Sarlo, Beatriz. "Debate sobre la ponencia de Beatriz Sarlo". Prismas. Revista de Historia Intelectual, n. ${ }^{\circ}$ 1, 1997, pp. 196-200.

Sarlo, Beatriz. El imperio de los sentimientos. Narraciones de circulación periódica en la Argentina, 1917-1927. Catálogos, 1985.

Sarlo, Beatriz. Escenas de la vida posmoderna. Intelectuales, arte y videocultura en la Argentina. Ariel, 1994.

Sarlo, Beatriz. Escritos sobre literatura argentina. Siglo XXI, 2007.

Sarlo, Beatriz. Ficciones argentinas: 33 ensayos. Mardulce, 2012.

Sarlo, Beatriz. Instantáneas. Medios, ciudad y costumbres en el fin de siglo. Ariel, 1996.

Sarlo, Beatriz. La audacia y el cálculo. Kirchner 2003-2010. Sudamericana, 2011.

Sarlo, Beatriz. La ciudad vista. Mercancias y cultura urbana. Siglo XXI, 2009.

Sarlo, Beatriz. La imaginación técnica. Sueños modernos de la cultura argentina. Nueva Visión, 1992.

Sarlo, Beatriz. La máquina cultural. Maestras, traductores y vanguardistas. Ariel, 1998.

Sarlo, Beatriz. La pasión y la excepción. Siglo XXI, 2003.

Sarlo, Beatriz. "Las dos preguntas de Mercedes". Viva, 22 de mayo de 2005, p. 58.

Sarlo, Beatriz. "Olvidar a Benjamin". Punto de Vista, n. ${ }^{\circ} 53$, noviembre de 1995, pp. 16-19.

Sarlo, Beatriz. "Paseo por la Ribera". Viva, 15 de mayo 2005, p. 56.

Sarlo, Beatriz. "Personaje”. Sección "Caza de citas". Página/30, n. 38, septiembre de 1993, pp. 24-25.

Sarlo, Beatriz. "Prólogo a la edición en español”. El campo y la ciudad, por Raymond Williams, Paidós, 2001, pp. 11-12.

Sarlo, Beatriz. Roberto Arlt, excéntrico. Los siete locos. Los lanzallamas, por Roberto Arlt, Fondo de Cultura Económica, 2000, pp. XV-XIX.

Sarlo, Beatriz. Siete ensayos sobre Walter Benjamin. Fondo de Cultura Económica, 2000.

Sarlo, Beatriz. Tiempo pasado. Cultura de la memoria y giro subjetivo. Siglo XXI, 2006.

Sarlo, Beatriz. Tiempo presente. Siglo XXI, 2001. 
Sarlo, Beatriz. Una modernidad periférica. Buenos Aires, 1920 y 1930. Nueva Visión, 1988.

Sarlo, Beatriz. "Veinte años después". Escenas de la vida posmoderna. Intelectuales, arte y videocultura en la Argentina. Siglo XXI, 2014, pp. 9-11.

Sarlo, Beatriz. Viajes. De la Amazonia a Malvinas. Seix Barral, 2014.

Sarlo, Beatriz. Zona Saer. Ediciones Universidad Diego Portales, 2016.

Speranza, Graciela. "Entrevista Beatriz Sarlo. Tres postales argentinas”. Clarin, 9 de abril de 1998, pp. 1-3.

Vázquez, María Celia. "Beatriz Sarlo, una crítica moderna". Las operaciones de la crítica, compilado por Alberto Giordano y María Celia Vázquez, Beatriz Viterbo, 1988, pp. 45-66.

Vázquez, María Celia. "Las interrogaciones de la crítica en el fin de siglo". CELEHIS. Revista del Centro de Letras Hispanoamericanas, n. ${ }^{\circ}$ 15, 2003, pp. 335-356.

\section{Anexo}

Sarlo, Beatriz. "Aprendiendo a escuchar”. Sección “Caza de citas”. Página/30, n. 59, junio de 1995, pp. 46-47. Sarlo, Beatriz. "Carteles y afiches”. Sección “Caza de citas”. Página/30, n. ${ }^{\circ}$ 60, julio de 1995, pp. 45-46.

Sarlo, Beatriz. "Caza de citas”. Página/30, n. . 63, octubre de 1995, pp. 48-49.

Sarlo, Beatriz. "Décadas”. Sección "Caza de citas”. Página/30, n. ${ }^{\circ}$ 66, enero de 1996, pp. $42-43$.

Sarlo, Beatriz. "Del inventor del Hacker". Sección "Cuadros de costumbres”. Página/30, n. ${ }^{\circ}$ 89, noviembre de 1997, pp. 46-47.

Sarlo, Beatriz. "Desde la panza”. Trespuntos, n. ${ }^{\circ}$ 3, 24 de julio de 1997, p. 61.

Sarlo, Beatriz. "Desventuras en el cyberespacio". Sección "Caza de citas”. Página/30, n. . 65, diciembre de 1995, pp. 58-59.

Sarlo, Beatriz. "Disfraces masculinos". Sección "Cuadros de costumbres”. Página/30, n. ${ }^{\circ}$ 77, diciembre de 1996, pp. 50-51.

Sarlo, Beatriz. "El barullo cultural". Trespuntos, n. ${ }^{\circ}$ 5, 7 de agosto de 1997, pp. 32-33.

Sarlo, Beatriz. "El gusto de los gustos". Sección "Caza de citas". Página/30, n. 56, marzo de 1995, pp. 52-53.

Sarlo, Beatriz. "El mal no es argentino". Sección "Cuadros de costumbres". Página/30, n. o 83, mayo de 1997 , pp. 58-59.

Sarlo, Beatriz. "El ocio en el Lejano Oeste". Trespuntos, n. ${ }^{\circ}$ 2, 17 de julio de 1997, pp. 34-37.

Sarlo, Beatriz. "El sacrificio". Trespuntos, n. ${ }^{\circ} 4,31$ de julio de 1997, pp. 40-41.

Sarlo, Beatriz. "Exageración”. Sección "Caza de citas”. Página/30, n. 69, abril de 1996, pp. 28-29.

Sarlo, Beatriz. "Fotos del verano". Sección "Caza de citas". Página/30, n. ${ }^{\circ}$ 54, enero de 1995, pp. 48-49.

Sarlo, Beatriz. "Games". Sección "Caza de citas”. Página/30, n. ${ }^{\circ}$ 39, octubre de 1993, pp. 68-69.

Sarlo, Beatriz. "La aventura de masas". Sección "Cuadros de costumbres". Página/30, n. ${ }^{\circ} 82$, abril de 1997, pp. 68-69.

Sarlo, Beatriz. “¿La escuela debe entrar en el show-business?”. Sección “Cuadros de costumbres”. Página/30, n. ${ }^{\circ}$ 74, septiembre de 1996, pp. 52-53.

Sarlo, Beatriz. "La historia compacta y la historia ausente". Sección "Cuadros de costumbres". Página/30, n. ${ }^{\circ} 86$, agosto de 1997 , pp. 44-45.

Sarlo, Beatriz. "La nación en el fin de siglo". Sección "Caza de citas". Página/30, n. 58, mayo de 1995, p. 9.

Sarlo, Beatriz. "La paradoja del rumor". Sección "Cuadros de costumbres”. Página/30, n. ${ }^{\circ} 79$, febrero de 1997, pp. 48-49.

Sarlo, Beatriz. "La parte perecedera de las cosas". Sección “Caza de citas”. Página/30, n. 49, agosto de 1994, pp. 44-45.

Sarlo, Beatriz. “La zona gris”. Sección “Cuadros de costumbres”. Página/30, n. ${ }^{\circ}$ 85, julio de 1997, pp. $52-53$. 
Sarlo, Beatriz. "Las dos naciones”. Sección "Caza de citas”. Página/30, n. o 51, octubre de 1994, pp. 44-45. Sarlo, Beatriz. “¿Loquitos argentinos?”. Sección “Cuadros de costumbres”. Página/30, n. ${ }^{\circ}$ 91, febrero de 1998, pp. 58-59.

Sarlo, Beatriz. "Los dadores de sentido". Sección "Cuadros de costumbres". Página/30, n. ${ }^{\circ}$ 76, noviembre de 1996, pp. 46-47.

Sarlo, Beatriz. "Los ocupantes de la noche”. Sección “Caza de citas". Página/30, n. 64, noviembre de 1995 , pp. 62-63.

Sarlo, Beatriz. "Milagros". Sección "Cuadros de costumbres”. Página/30, n. 9 90, enero de 1998, pp. $42-43$.

Sarlo, Beatriz. "Nadie es perfecto y sin embargo...”. Sección "Cuadros de costumbres”. Página/30, n. ${ }^{\circ}$ 80, marzo de 1997, pp. 54-55.

Sarlo, Beatriz. "No hay re-drama, ¿viste?”. Sección "Cuadros de costumbres”. Página/30, n. ${ }^{\circ}$ 73, agosto de 1996, pp. 56-57.

Sarlo, Beatriz. "Pop romántico". Sección "Cuadros de costumbres". Página/30, n. 84, junio de 1997 pp. 62-63.

Sarlo, Beatriz. "Que se vayan”. Trespuntos, n. ${ }^{\circ}$ 9, 4 de septiembre de 1997, pp. 18-19.

Sarlo, Beatriz. "Queridos niños”. Página/30, n. * 46, mayo de 1994, pp. 60-61.

Sarlo, Beatriz. "Regalos”. Sección “Caza de citas”. Página/30, n.o 42, enero de 1994, pp. 64-65.

Sarlo, Beatriz. "Reyes del cool”. Sección “Caza de citas”. Página/30, n. 68, marzo de 1996, pp. 52-53.

Sarlo, Beatriz. "Sexo oral”. Sección “Caza de citas”. Página/30, n. o 47, junio de 1994, pp. 58-59.

Sarlo, Beatriz. "Shakespeare. Alcón y la fábula del zorro". Trespuntos, n. ${ }^{\circ}$ 1, 10 de julio de 1997, pp. 44-45.

Sarlo, Beatriz. “Televisar”. Sección “Caza de citas”. Página/30, n. 40, noviembre de 1993, pp. 38-39.

Sarlo, Beatriz. “¿Todo lo sólido se desvanece en el aire?". Sección "Caza de citas”. Página/30, n. 62 , septiembre de 1995, pp. 46-47.

Sarlo, Beatriz. "Un día provechoso". Sección “Caza de citas”. Página/30, n. 57, abril de 1995, pp. 44-45.

\section{Notas}

* Artículo de investigación. Este trabajo se terminó de escribir en mayo de 2017; por lo tanto, no incorpora el libro de Beatriz Sarlo, La intimidad pública, Seix Barral, 2018, que se publicó un año después.

1 “Me parece peligroso - afirma Sarlo- que un universitario no pueda, dicho sea entre comillas, 'perder su tiempo' dedicándose a pensar la política, la cultura, los medios de comunicación, los sectores populares. Que la crítica literaria sea un discurso autosuficiente me parece sumamente peligroso. Los grandes críticos de este siglo no han ejercido este discurso, si es que los grandes críticos son para nosotros Auerbach, Sartre, Roland Barthes, Bajtín” (Reynoso 59).

2 En una nota al pie de Instantáneas, Sarlo dice que comenzó a escribir en Página/30 en octubre de 1994, invitada por Rodrigo Fresán y Eduardo Blaustein. Sin embargo, su columna empieza un año antes, en septiembre de 1993 (7).

3 Dice Sarlo: "Me di cuenta de que este era mi año número 20 en la facultad, y mi vida no estuvo programada para estar 20 años en ninguna parte. Preparar las clases, enfrentarme con los 400 alumnos, era cada vez más una pesadilla. Sentía que tenía que probar todo el tiempo que estaba ahí por algo, cosa que no me pasaba en 1984 cuando sabía un tercio de lo que aprendí dando clase" (Canavese 51).

4 Escribe Sarlo en 2014, en la reedición de Escenas de la vida posmoderna: "Los dos últimos capítulos de este libro tratan, uno sobre artistas y el otro sobre intelectuales. En esos capítulos estoy yo misma y está el mundo al que pertenezco. Desde allí, desde las observaciones sobre ideología y estética, sobre 'vida de artista' y 'vida de intelectual', desde ese suelo para mí originario, avancé por el territorio menos conocido. Los dilemas de la estética y la ideología siguen interesándome, hasta hoy, tanto como los de las culturas mediáticas y tecnológicas. En ese sentido, el libro esconde (o muestra) un camino biográfico” (11).

5 Para un estudio de "las razones biográficas", véase Freire.

6 Escribe Sarlo: "Faltan unos quince minutos para que comience el espectáculo. En la sala que va llenándose poco a poco, rebotes de luz dorada modulan el terciopelo rojo. Desde la llamada cazuela, es decir el segundo nivel en altura, se ven en perspectiva los respaldos ovales de las butacas de platea, con sus marcos de madera oscura, donde una perchita de bronce se ofrece eventualmente para sostener una cartera. Del costado que ocupo en ese segundo nivel del teatro, puedo ver el palco presidencial, ubicado exactamente en el centro, sobre la entrada de la platea; en su frente, el escudo nacional 
señala el mejor lugar del teatro Colón. Muchas veces no hay nadie allí, pero esta noche, en que se canta El oro del Rhin de Richard Wagner, el palco presidencial está casi lleno” (“iAl Colón!” 58).

7 Por ejemplo, escribe: "La sala es la del Teatro de la Ribera, donde hay varios murales de Quinquela Martín, iconografía de la época en que la Boca fue un barrio de inmigrantes y trabajadores del puerto. El teatro está a una decena de metros del puente transbordador, esa maravilla técnica, que hoy parece la instalación urbana de un mecanismo gigantesco y obsoleto. Graciela Silvestri, en su libro sobre la Boca, lo compara con la torre Eiffel, aunque, a diferencia de la torre Eiffel, señala que el transbordador no fue una construcción festiva, sino utilitaria, que aún conserva la sombra del trabajo y la fatiga. La obra de Giménez se ubica bien en este espacio, porque elabora napas de la cultura popular italiana y argentina" ("Paseo" 56). "Algo que debemos agradecer, además a la escritura de Sarlo, es la ausencia de parafernalia académica. Salvo en contadas ocasiones donde aparecen ideologemas y otras hierbas de la misma especie, o en los textos que preceden a los estudios referidos a los escritores actuales, nos exime, afortunadamente, de los rizomas y deconstrucciones con que suelen desconcertarnos algunos de sus colegas, que hacen de la crítica literaria una suerte de púlpito científico anexo a sus cátedras" (Bordelois).

9 Para un análisis de las estrategias discursivas de Sarlo en los medios masivos, véase Vázquez ("Las interrogaciones").

10 Para las relecturas de Sarlo sobre sí misma, véase Mondragón.

11 "Ricardo Ibarlucía creyó que yo debía escribir este libro y así me lo hizo saber" (Escenas 199); "He vuelto a releer esos artículos, rescatados de unas carpetas bastante desprolijas por Carlos Díaz, el editor de este libro” (Tiempo presente 9); "Fue a Sylvia Saítta a quien primero se le ocurrió este libro" ( Escritos sobre literatura 11); "Pablo Avelluto tuvo la idea de que escribiera este libro, algo que se volvió evidente solo cuando él lo sugirió” (La audacia 9); "Cuando Maximiliano Tomas estuvo algunos meses afuera, Damián Tabarovsky lo reemplazó en la tarea de editar el suplemento y ahora se le ocurrió a Damián que las agrupáramos en este libro" (Ficciones argentinas 11).

\section{Licencia Creative Commons CC BY 4.0}

Cómo citar: Saítta, Sylvia. "Algunos intentos por escribir sobre Sarlo". Cuadernos de Literatura, vol. 24, n. ${ }^{\circ}$ 47, 2020, https://doi.org/10.11144/Javeriana.cl24.aibs 